\title{
Semântica do acontecimento e agenciamento enunciativo: um exercício de análise
}

\author{
Nathan Bastos de Souza* \\ UFSCar \\ Recebido em: 20/04/2019 \\ Aceito em: 22/11/2019
}

\begin{abstract}
Resumo: Pautando-nos na Semântica do acontecimento de Eduardo Guimarães, especialmente nos conceitos de acontecimento, agenciamento do sujeito, reescrituração e articulação, estudamos os sentidos de uma matéria de jornal sobre o último disco de Mercedes Sosa. Na análise discute-se que o Locutor assina o texto como um locutor x que ocupa um espaço de crítico, mas não independentemente, é um crítico brasileiro que escreve em um jornal que circula no Brasil. Assim, seu dizer é constituído por uma contradição: enuncia seu projeto de não ufanismo, enfatizando elogiosamente a participação de cantores brasileiros e avalia negativamente o trabalho de cantores estrangeiros.
\end{abstract}

Palavras chave: Semântica do acontecimento. Agenciamento enunciativo. Mercedes Sosa.

Abstract: Based on Semantics of Event by Eduardo Guimarães, especially on the concepts of event, agency of the subject, rewriting and articulation, we studied the senses of a newspaper article about Mercedes Sosa's lastest album. The analysis discuss that the Locutor signs the text as an $\mathrm{x}$-Locutor that occupy a critical space, but not independently, it is a Brazilian critic writing in a newspaper that circulates in Brazil. Thus, his saying is constitutive by a contradiction: it enunciates its project of non ufanism, praising the Brazilian singers' participation and negatively evaluating the work performed by foreing singers.

Keywords: Semantics of event. Enunciative agency. Mercedes Sosa.

Resumen: Pautándonos en la Semántica del acontecimiento de Eduardo Guimarães, especialmente en los conceptos de acontecimiento, agenciamiento del sujeto, reescrituración y articulación, estudiamos los sentidos de una materia periodística sobre el lanzamiento del último disco de Mercedes Sosa. En el análisis se discute que el Locutor firma el texto como un locutor $\mathrm{x}$ ocupando un espacio de crítico, pero no independientemente, como un crítico brasilero escribiendo en un periódico que circula en Brasil. Su decir se constituye contradictoriamente: enuncia su proyecto de no chovinismo, enfatizando elogiosamente la participación de cantores brasileros y evalúa negativamente el trabajo de cantores extranjeros. Palabras clave: Semántica del acontecimiento. Agenciamiento del sujeto. Mercedes Sosa.

\section{Introdução}

A teoria da semântica da enunciação, desenvolvida pelo linguista brasileiro Eduardo Guimarães, cuja perspectiva é herdeira da reflexão de O. Ducrot e É. Benveniste, trabalha com o sentido de modo diverso em relação às semânticas 
referencialistas. O conceito central mobilizado pela teoria é o de enunciação e nele se ancoram as restantes noções desenvolvidas, como sujeito, acontecimento, cena enunciativa, designação, entre outros (SCHREIBER DA SILVA; MACHADO, 2016, p. 74). Destarte, para Guimarães (2002), o sentido é produzido enunciativamente no e pelo acontecimento da enunciação.

Para essa perspectiva, os procedimentos de produção de sentido são de dois tipos, a reescrituração e a articulação. Guimarães (2009) explica que o dispositivo específico de sua análise semântica leva em conta o enunciado como unidade, afirmando que "uma sequência linguística só é enunciado enquanto uma unidade de sentido que integra um texto" (GUIMARÃES, 2009, p. 50). Portanto, a análise semântica que se leva a cabo considera a relação de sentido estabelecida pelas sequências linguísticas em relação com o exterior, particularmente a relação dessas unidades específicas com o texto em que figuram, tomando a noção de integração do trabalho de Benveniste (2005) e expandindo o escopo dessa abordagem².

O objetivo deste artigo é estudar a produção de sentidos de um texto, qual seja um artigo de opinião publicado no caderno Cultura do jornal digital O Globo, em que se trata do lançamento do CD e DVD de Mercedes Sosa, "Cantora". Para tanto, mobilizamos os conceitos de acontecimento, agenciamento do sujeito, reescrituração e articulação desenvolvidos por E. Guimarães na análise do texto entendido como um todo. Primeiramente, nos dedicamos à descrição do texto, analisando as formas de reescrituração; em um segundo momento, aventamos as relações de articulação e discutimos a perspectiva de agenciamento do sujeito que funciona contraditoriamente. Em nossa análise apontamentos que o Locutor que assina esse texto, diz como um locutor x que ocupa um espaço de crítico, mas sua tarefa não é à revelia, já que escreve a respeito de um lançamento estrangeiro para brasileiros em um jornal que circula, sobretudo, no Brasil. Assim, o seu dizer é atravessado por uma contradição constitutiva, uma vez que enuncia seu projeto de não ufanismo e o produz discursivamente, dando ênfase à participação de cantores brasileiros no disco e avaliando negativamente o trabalho realizado com outros cantores estrangeiros.

\footnotetext{
${ }^{1}$ Os níveis de análise linguística para Benveniste (2005) vão até, no limite, a análise da frase. A proposição de Guimarães ao longo de sua reflexão é chegar com a noção de integração a contribuir para a análise de textos, portanto, de uma unidade analítica maior que aquela aventada pelo estruturalista francês.
} 
Justificamos este trabalho como um exercício de análise que busca contribuir para uma aplicação da teoria e dos procedimentos analíticos desenvolvidos pelo linguista brasileiro E. Guimarães. Assim, trata-se de um esforço de divulgação na medida em que se vale de uma teoria desenvolvida no Brasil para analisar dados que são de acesso ao público em geral.

Este artigo está dividido em quatro partes que se completam: na primeira seção, apresentamos as discussões desenvolvidas na teoria da semântica enunciativa sobre o conceito de acontecimento e sobre o agenciamento do sujeito. A segunda seção é reservada à apresentação dos procedimentos de análise, que é desenvolvida propriamente na seção seguinte. Ao final, apresentamos algumas considerações finais e referências utilizadas.

\section{Acontecimento e agenciamento do sujeito}

Conforme Guimarães (2002, p. 11) "a enunciação, enquanto acontecimento de linguagem, se faz pelo funcionamento da língua”. Assim, há alguns elementos decisivos para a constituição dessa perspectiva semântica, quais sejam, "a língua e o sujeito que se constitui pelo funcionamento da língua na qual enuncia-se algo” (p.11). A esses dois elementos decisivos o autor adiciona mais dois: a temporalidade e o "real a que o dizer se expõe ao falar dele" (p.11).

O acontecimento, por sua parte, é definido como "o que faz diferença na sua própria ordem" (GUIMARÃES, 2011, p. 15) e que é constituído pela temporalidade. O autor afirma que,

\footnotetext{
Assim, um acontecimento não é considerado em virtude de estar num certo momento no tempo, antes de um outro acontecimento também no tempo. O que especifica um acontecimento é a temporalidade que ele constitui: um passado, um presente e um futuro. Ou seja, um acontecimento é diferente de outro porque recorta um passado de sentidos que convive com o presente da formulação do Locutor e assim traz uma projeção de futuro de sentidos que não significariam não fosse o acontecimento em questão (GUIMARÃES, 2011, p.15).
}

Nesse ínterim, a semântica enunciativa propõe um deslocamento em relação à teoria de Benveniste (2005), que dá centralidade ao sujeito, porque o desafio de seu conceito de enunciação é duplo “i) não colocar o sujeito como centro da enunciação, 
mas tratar a subjetividade no âmbito do social, do histórico e do político; ii) inserir a história não como sequência (cronológica) de fatos mas, como historicidade" (SCHREIBER DA SILVA; MACHADO, 2016, p. 73). Em outros termos, o afastamento produzido é no sentido de que o sujeito é agenciado a dizer, porque sua enunciação é constituída pelas formas da língua social e historicamente dadas.

Se no trabalho de Benveniste (2005) o marco de temporalidade é constituído pelo locutor que diz "eu", instaurando uma alocação com "tu", na reflexão de Guimarães (2002, p.12) "não é o sujeito que temporaliza, é o acontecimento": à diferença do autor francês, o acontecimento demarca a temporalidade e o sujeito é tomado no acontecimento. A questão da temporalidade é discutida nos seguintes termos:

\begin{abstract}
De um lado ela se configura por um presente que se abre em si uma latência de futuro (uma futuralidade), sem a qual não há acontecimento de linguagem, sem a qual nada é significado, pois sem ela (a latência de futuro) nada há aí de projeção, de interpretável. O acontecimento tem como seu um depois incontornável, e próprio do dizer. Todo acontecimento de linguagem significa porque projeta em si mesmo um futuro.Por outro lado este presente e futuro próprios do acontecimento funcionam por um passado que os faz significar. $\mathrm{Ou}$ seja, esta latência de futuro, que, no acontecimento, projeta sentido, significa porque o acontecimento recorta um passado como memorável (GUIMARÃES, 2002, p.12).
\end{abstract}

O acontecimento está ligado à enunciação e, portanto, "não é exterior à língua” (SCHREIBER DA SILVA; MACHADO, 2016, p. 74) e "não é sempre o novo, [é, por outro lado,] o encontro do já dito (memória de sentidos) com os sentidos produzidos na enunciação" (p. 74). Nessa perspectiva semanticista, o real é recortado pela enunciação que recupera os sentidos do passado e projeta uma futuridade. É por esse motivo que o "o acontecimento é sempre nova temporalização [...] sem a qual não há sentido, não há acontecimento de linguagem, não há enunciação" (GUIMARÃES, 2002, p. 12).

No que se refere ao agenciamento do sujeito que é produzido no acontecimento, Guimarães (2009) considera que a análise de qualquer expressão linguística deve ser considerada em "uma relação do locutor com aquilo que ele fala" e por uma "relação entre os elementos linguísticos" (p. 50). Em outras palavras,

[...] não é o Locutor que escolhe uma forma para dizer algo, mas ele é agenciado a dizer pelo modo como as formas linguísticas se constituíram sóciohistoricamente e pelo modo como o espaço de enunciação distribui as 
línguas, e os modos de dizer e o que dizer, para seus falantes (GUIMARÃES, 2009, p.50).

O locutor, portanto, é agenciado por questões que estão no exterior, que são da ordem do social, do histórico e do político. Esses aspectos são tomados no sentido de um passado que faz significar, daí que o "O Locutor só [seja] Locutor enquanto falante determinado por este espaço político do dizer, o espaço de enunciação" (GUIMARÃES, 2009, p. 50). Nesse sentido, não é figura homogênea ou empírica, mas determinada pela relação de línguas presentes no espaço da enunciação. Esse espaço dos acontecimentos enunciativos produz algumas figuras:

[...] o Locutor (L), enquanto figura que se representa como responsável pelo dizer; o locutor-x, enquanto lugar social do dizer; e o enunciador, enquanto lugar de dizer, o lugar de onde se diz. E é nessa medida que, do ponto de vista semântico, podemos dizer que o funcionamento das expressões linguísticas são lugares de produção de sentido (GUIMARÃES, 2009, p.50).

Segundo o autor, para que o Locutor (com maiúscula) se represente como origem do que é enunciado, "é preciso que ele seja agenciado por um lugar social de locutor" (GUIMARÃES, 2011, p. 23). O exemplo do Presidente da República é pertinente, porque ao assinar qualquer ato o Presidente Decreta $\mathrm{X}$, não porque ele enquanto sujeito empírico assuma e dê a si mesmo a autoridade de originar qualquer coisa que tenha peso de decreto, mas porque é "autorizado a se dar como origem do próprio ato de decretar" (p.23). Em outras palavras, o Locutor presidente "só pode falar enquanto predicado por um lugar social” (p.23), que é o locutor x.

Guimarães (2009) argumenta que os procedimentos de agenciamento enunciativo são de dois tipos: de articulação e de reescrituração. Primeiramente, explicando o primeiro mecanismo, o autor pontua que a articulação é

[...] o procedimento pelo qual se estabelecem relações semânticas em virtude do modo como os elementos linguísticos, pelo agenciamento enunciativo, significam sua contiguidade. Ou seja, a organização das contiguidades linguísticas se dá como uma relação local entre elementos linguísticos, mas também e fundamentalmente por uma relação do Locutor (enquanto falante de um espaço de enunciação) com aquilo que ele fala (GUIMARÃES, 2009, p.5o). 
A articulação pode acontecer de três maneiras nos textos e a seguir esboçamos um esquema:

1) Por dependência, quando elementos contíguos constituem um só conjunto; exemplo: em "Os meninos de vermelho" a relação entre o determinante "os" e "de vermelho" conforma com "meninos" uma única unidade, um grupo nominal; (GUIMARÃES, 2009, p.50).

2) Por coordenação, quando "se apresenta por um processo de acúmulo de elementos numa relação de contiguidade" (GUIMARÃES, 2009, p.50). Exemplo: "os meninos e as meninas";

3) Por incidência, "incidência é a relação que se dá entre um elemento de uma natureza e outro de outra natureza, de modo a formar um novo elemento do tipo do segundo" (GUIMARÃES, 2009, p.50). Exemplo: “Até Pedro veio", em que o advérbio "até" incide no todo do enunciado. A incidência se dá sem uma dependência estabelecida, porque "Pedro veio" já é enunciado sem o advérbio, que não constitui enunciado isoladamente (GUIMARÃES, 2009, p. 51).

O segundo procedimento de agenciamento enunciativo é, segundo o autor, o de reescrituração. Esse procedimento consiste em redizer o que já foi dito: uma palavra ou expressão linguística retoma outra "por algum procedimento que as relaciona no texto integrado pelos enunciados em que ambas estão" (GUIMARÃES, 2009, p.51). A reescrituração se caracteriza por "fazer interpretar uma forma (reescriturada) como diferente de si (em virtude da reescrituração)" (p.51). Em outras palavras, o elemento que repete deve ser tomado como novo (Cf. GUIMARÃES, 2013, p.29). A reescrituração não exige relações de continuidade entre os enunciados, porque relaciona parte de uns e outros enunciados do texto. Por fim, "é um processo enunciativo que percorre transversalmente o texto, independentemente de qualquer segmentalidade direta" (GUIMARÃES, 2013, p. 31).

Para caracterizar a relação entre o elemento reescriturado e o que reescreve, Guimarães (2009) afirma que se trata de "uma relação transitiva, simétrica e nãoreflexiva" (GUIMARÃES, 2009, p. 53). Consideremos os três seguintes enunciados²: a) "Paulo viajou ontem. Deve estar em São Paulo na quinta. Ele deve voltar no final de

${ }^{2}$ Exemplo formulado por Guimarães (2009). 
semana”. Nesse exemplo, a reescrituração é simétrica porque Paulo do primeiro enunciado reescreve ele do terceiro na mesma medida em que ele reescreve Paulo. A relação de sentido aqui estabelecida é de integração ao texto, não é, portanto, uma relação de ordenação. b) Há uma relação transitiva entre os elementos de reescrituração nos três enunciados porque Paulo, do primeiro enunciado, a elipse de Paulo, no segundo, e ele, no terceiro, se reescrevem funcionando à distância e transversalmente, características da reescrituração. c) Há uma relação não-reflexiva na medida em que Paulo, do primeiro enunciado, não é igual a ele, do terceiro. Esse raciocínio vale também para o caso de repetição, por exemplo, se houvesse nos enunciados uma reescrituração do tipo Paulo(1) e Paulo(2), em virtude de ser uma repetição, também significa diferente, portanto, não há uma relação reflexiva.

A reescrituração se dá de alguns modos, que esquematizaremos seguindo Guimarães (2007):

a) Repetição: retomada da mesma expressão linguística, que pode se dar inteiramente ou por redução (p. 85).

b) Substituição: "uma expressão é retomada em outro ponto por outra expressão" (GUIMARÃES, 2007, p.85). Um modo muito particular de substituição é a anáfora.

c) Elipse: omissão de uma expressão linguística, que não é substituída nem repetida na enunciação.

d) Expansão: é uma forma de ampliar uma expressão nominal. Exemplo: no texto de Guimarães (2007, p.85), o título do texto “Operação Sanguessuga” é expandido no primeiro parágrafo, ou seja, “Operação Sanguessuga” é reescrito por expansão pelo primeiro parágrafo do texto que integra.

e) Condensação: uso de uma expressão linguística que evite a repetição de alguma parte maior do texto (p. 85).

f) Definição: quando a reescrituração é um modo de definir o termo (p. 85).

\section{Procedimentos de análise}

Para realizarmos nossa análise semântica conforme os parâmetros ora levantados trabalharemos de acordo com o seguinte procedimento geral de análise: 
1) Toma-se um recorte qualquer e produz-se uma descrição de seu funcionamento;

2) Interpreta-se seu sentido na relação com o texto em que está integrado;

3) Chega-se a, ou toma-se, outro recorte e faz-se dele uma descrição;

4) Interpreta-se seu sentido na relação com o texto em que está integrado, tendo em vista a interpretação feita do primeiro recorte.

5) Busca-se um novo recorte, etc. até que a compreensão produzida pelas análises se mostre suficiente para o objetivo específico da análise. (GUIMARÃES, 2011, p. 45).

Nessa perspectiva, realizaremos uma análise da notícia "Sai DVD do último trabalho de Mercedes Sosa”, de autoria de Antônio Carlos Miguel, publicada em 25 de novembro de 2009, no jornal O Globo. Trata-se de um texto 3 com oito parágrafos que será analisado por nós na íntegra, balizando nossa reflexão nas categorias de reescrituração e articulação para descrever o acontecimento enunciativo ali presente. Nesse sentido, em um primeiro momento, fazemos uma descrição geral do texto verbal contido nos parágrafos do texto, demonstrando os procedimentos de reescrituração; em um segundo momento, trabalhamos com a noção de articulação dos enunciados no texto em análise, nesse sentido, destacamos relações de sentido constantes no texto (verbal e imagético) que o atravessam. Por fim, no enlace entre ambos os procedimentos de agenciamento do sujeito apresentamos essa discussão sobre o ufanismo e seu funcionamento contraditório no texto.

\section{Procedimentos de agenciamento do sujeito no funcionamento do texto}

Primeiramente, sobre a divisão do falante, neste texto propomos que é divido da seguinte maneira: o Locutor (L) do texto é Antônio Carlos Miguel, o locutor x, o lugar social do dizer, é representado por sua enunciação neste texto como crítico musical, e o enunciador do texto, como lugar de dizer, é o caderno Cultura do jornal O Globo, em que foi publicado. Em outras palavras, Antônio Carlos Miguel (sujeito empírico) é agenciado pelo lugar social do dizer (locutor-crítico musical) no texto como crítico musical, em um lugar de dizer que é o caderno sobre cultura do referido jornal.

É importante perceber que o funcionamento deste texto se dá como um acontecimento, porque, no dizer de Guimarães (2011), "recorta um passado de sentidos

${ }^{3}$ Há uma imagem em primeiro plano no texto, logo abaixo do título, que serve para corroborar nossa análise. 
que convive com o presente do Locutor" (p.15), de maneira que a enunciação projeta, por sua vez, um futuro de sentidos. A retomada de sentidos em um memorável que faz os enunciados significar se dá em função do próprio acontecimento da enunciação, que constitui uma temporalidade e divide o que é anterior - passado - a sua emergência presente - e sua projeção - futuro. É nesse sentido que Guimarães (2002) afirma que um enunciado é uma diferença na própria ordem.

Faremos a seguir uma análise pontual de cada um dos parágrafos sempre em relação ao texto que integram. O texto completo está disponível no anexo 1 deste artigo e preferimos para os fins analíticos reproduzir apenas as passagens de que estamos tratando no bojo do texto.

O primeiro parágrafo do texto iniciando com a ordem sintática inversa colocando os complementos "Num de seus depoimentos, no documentário em DVD que acompanha o disco "Cantora" (Sony Music)" diante do sintagma nominal (SN) principal "Mercedes Sosa diz que..." - introduz uma hipótese que nossa análise defende: os discursos sobre Mercedes Sosa estão de tal maneira inscritos no memorável que é preciso retomar seu nome como sujeito responsável pelo DVD apenas poucas vezes e muitas outras vezes de maneira indireta.

O primeiro parágrafo do texto aproveita-se da proximidade com o título e com a legenda da fotografia que integra a notícia - que retomariam anaforicamente Mercedes Sosa ${ }^{4}$ - e desloca o SN principal "Mercedes Sosa diz que..." para uma posição secundária na sintaxe da enunciação, produzindo um efeito de que a informação que é complementar sintaticamente sobre os depoimentos que dá no DVD "Cantora" seja mais importante que o SN, por isso a anteposição. Esse mesmo parágrafo funciona como um balanço dos argumentos que o crítico levanta ao longo do texto: não basta a ideologia - como a cantora afirmou no documentário - para ser uma boa intérprete, é preciso mais. O SN principal dessa primeira oração introduz a seguinte consideração: "Mercedes Sosa diz que, se não fosse a ideologia, ela seria apenas mais uma cantora. Verdade confirmada por seu trajeto e sua postura política, mas que também permite uma observação contrária: não fosse uma grande intérprete, com seu belo timbre de

\footnotetext{
${ }^{4}$ Voltaremos a tratar mais adiante na análise do papel dessa fotografia na produção de sentidos dessa notícia.
} 
contralto, e a sensibilidade na escolha de repertório e acompanhantes, ela não passaria de mais uma artista engajada”.

Como o texto que analisamos está disponível na web, há um hiperlink de um vídeo do YouTube, em que Mercedes Sosa canta com Caetano Veloso uma das canções gravadas no CD e DVD de que se dá notícia na publicação. O nome da cantora é aí reescriturado por repetição, "Mercedes Sosa”. Voltaremos a esse ponto adiante, mas o tratamos como um parágrafo, o segundo, para fins de análise.

No terceiro parágrafo, chama atenção o fato de que o nome da artista não aparece nenhuma única vez, seja repetido "Mercedes Sosa", seja reescriturado por redução "Mercedes”. Aparece apenas substituído por “voz”, em "dessa voz" e reescrito por anáfora nos pronomes possessivos "seu”, em "Seu canto de cisne", e "seus" em "seus convidados".

No que se refere ao quarto parágrafo, há uma reescrituração por condensação do nome da artista "Mercedes" que aparece justaposta a uma reescrituração por expansão sobre sua biografia "então com 73 anos e muitos quilos a mais, sempre sentada - seja nas entrevistas ou gravando -, tinha experiência e talento para driblar as dificuldades físicas”, na qual, ainda, aparece uma reescrituração por elipse em “[Ø] tinha experiência...”. Há uma reescrituração por substituição “cantora”, outra por substituição anafórica realizada pelo pronome possessivo em “sua morte”.

O quinto parágrafo critica o conceito de "folclórico", que premiou o álbum em análise pelo Locutor, e ao fazer isso não reescreve por repetição ou condensação o nome da artista nenhuma vez, apenas lança mão de reescriturar por sinonímia com o termo "intérprete", que é reescriturado por expansão em "nascida em 9 de julho de 1935, em Tucumán, e que lançou seu primeiro LP em 1962, 'La voz de lazafra”. O restante do parágrafo se reduz a criticar as canções do repertório que são, para o Locutor, "monocórdias, com melodias por demais escravas de suas letras, um mal frequente na produção desses chamados cantautores", esse fragmento nos ajuda a interpretar o lugar social de dizer que agencia o Locutor como uma posição de alguém iniciado na crítica musical, coisa denunciada pelo jargão técnico e pelo conhecimento especificamente sobre o conceito de folclórico.

O parágrafo seguinte é aquele em que se trata do encontro com Caetano Veloso, ao final desse parágrafo o nome da cantora é reescriturado por condensação em “[...] 
Mercedes canta num português com leve sotaque”, por substituição em "a passagem da argentina pelo Brasil”. No parágrafo seguinte, referente à canção presente no disco e gravada em dueto com Daniela Mercury, não há nenhuma reescrituração do nome da cantora argentina.

No último parágrafo, todavia, o Locutor volta a reescrever o nome da cantora por condensação "Mercedes", por substituição “ela”. O último enunciado desse parágrafo, "Não basta ser engajado", se articula com o argumento invocado na introdução do texto (primeiro parágrafo), de que Mercedes Sosa falou em seu documentário que sem a ideologia seria apenas mais uma cantora. Em outras palavras, no primeiro parágrafo se trata do assunto de que Mercedes não foi apenas mais uma artista engajada, porque aliou a sua voz poderosa, um repertório e uma trajetória política distintos dos demais "engajados".

Analisando o texto globalmente, agora que temos uma descrição das reescriturações do nome da cantora que encontramos nos parágrafos, podemos tecer algumas questões que dizem respeito às operações de articulação dos enunciados. $\mathrm{O}$ efeito de apagamento do nome da cantora produzido por diferentes mecanismos enunciativos que apontamos acima (via reescrituração) assinala o memorável que recorta o passado. Em outras palavras, não é preciso que insistentemente o Locutor repita o nome "Mercedes Sosa” ou apenas "Mercedes" porque pode reescrever, por exemplo, por “cantora” (parágrafo 4), “intérprete” (parágrafo 5), “argentina” (parágrafo 6), ou simplesmente "voz" (parágrafo 3) e todas essas formas designam "Mercedes Sosa” corretamente e o leitor compreende essa reescrituração porque ela se inscreve no memorável a respeito dessa artista. No tocante ao acontecimento desse texto, a temporalidade em que se inscreve auxilia para que o leitor possa acessar essas informações reescrituradas pelos procedimentos apontados acima. Dito de outro modo, sem um memorável recortado pelo acontecimento da enunciação essas reescriturações não significariam. O acontecimento só adquire sentido quando temporaliza, faz isso recortando um passado de sentidos a que se contrapõem em sua formulação, em concomitância com um presente do Locutor e em projeção de um futuro de sentidos.

No que se refere à articulação, Guimarães (2011) afirma que é "o procedimento pelo qual se estabelecem relações semânticas em virtude do modo como os elementos 
linguísticos significam sua contiguidade” (GUIMARÃES, 2011, p. 45). Assim, à análise que fizemos do funcionamento da reescrituração no primeiro parágrafo do texto devem ser adicionadas algumas informações, já que ao analisarmos os procedimentos de reescrituração apenas trabalhávamos com o texto verbal ${ }^{5}$ e para a análise específica do procedimento de articulação levaremos em conta as relações semânticas dos elementos que integram o texto (títulos, imagem, informações complementares).

A ordenação do texto é título $\rightarrow$ fotografia $\rightarrow$ legenda $\rightarrow$ parágrafos. Se seguirmos essa ordem, o nome "Mercedes Sosa” é reescriturado por repetição pelo título, pela legenda da foto e no primeiro parágrafo. A fotografia também pode servir como apoio à análise da articulação, já que integra o texto e reescreve "Mercedes Sosa", mesmo que valendo-se de um texto imagético. Por fim, o hiperlink que redireciona ao vídeo, que chamamos para fins de análise de segundo parágrafo, reescreve por repetição "Mercedes Sosa". Em função dessas reescriturações por repetição - todas muito próximas, já que estão justapostos o título, a fotografia, a legenda e os dois parágrafos em que figura - o terceiro parágrafo vale-se, apenas, de reescrituração por substituição por meio de anáfora e sinonímia; do quarto parágrafo em diante a reescrituração do nome da cantora, quando aparece, é por condensação "Mercedes", em função da contiguidade do próprio texto.

A expressão "Seu canto de cisne" reescreve por condensação "último trabalho" que está presente no título do texto "Sai DVD do último trabalho de Mercedes Sosa" e remete a uma situação exterior à enunciação. O uso do verbo conjugado no presente do indicativo - "sai" - pode sugerir ambiguidade de que a cantora ainda trabalha e virão, depois desse trabalho, outros; no entanto, a reescritura por condensação feita pela expressão "Seu canto de cisne" também articula o fato de que no momento em que a notícia é publicada - novembro de 2009 - a cantora não trabalhava mais, já havia falecido há um mês, como virá expresso no quarto parágrafo. Portanto, as expressões "Seu canto de cisne" (terceiro parágrafo) e "sua morte" (quarto parágrafo), desfazem a ambiguidade sugerida pelo verbo no presente do indicativo do título que poderia sugerir que "último trabalho" designa "atual trabalho" e não "trabalho final".

Sobre a introdução no sexto parágrafo da expressão "sem ufanismo", podemos dizer que ela se articula contraditoriamente com o que o Locutor movimenta em seu

${ }^{5}$ Trabalhávamos especificamente com a análise dos parágrafos do texto. 
texto: "Sem ufanismo, um dos destaques é o encontro com Caetano Veloso em 'Coração vagabundo', faixa gravada no Rio, aproveitando a passagem da argentina pelo Brasil em outubro de 2008, quando recebeu a insígnia da Ordem do Mérito Cultural, em cerimônia realizada no Teatro Municipal. Juntos no estúdio, eles saboreiam os desenhos melódicos da velha pérola de Caetano, que Mercedes canta num português com leve sotaque". Ressaltamos desse excerto o uso de "sem", com essa palavra o lugar de dizer coletivo (de brasileiro) é obliterado, de modo a se isentar de opinião. Assim, com o uso de "sem", temos um enunciador individual sustentado pelo lugar social de crítico musical brasileiro.

Na medida em que o Locutor quer se propor como imparcial - isto é, não destacando o papel de cantores brasileiros "Sem ufanismo..." - como crítico, ele é agenciado pelo lugar de dizer que é um jornal brasileiro que veicula seu texto. Nesse sentido, o locutor que se propõe contraditoriamente como não ufanista dedica os parágrafos 6 e 7 inteiros à participação, respectivamente, dos cantores Caetano Veloso e Daniela Mercury. Também, destaque-se o fato de haver um hiperlink específico, como segundo parágrafo do texto, em que se pode acessar diretamente a canção gravada por Caetano com Mercedes nesse disco. Não fosse suficiente para demonstrar o agenciamento que sofre o locutor a dizer, mesmo afirmando não querer cometer em sua crítica a parcialidade de comentar com mais atenção o trabalho de cantores brasileiros, a fotografia que é vista logo abaixo do título também é de Mercedes com Caetano.

A preferência do Locutor se dá, pela ordem que aparece no texto e pela quantidade de informação dedicada, à participação de Caetano no disco (presente na fotografia, no hiperlink e em um grande parágrafo elogioso). Não por acaso, na enunciação do texto, o parágrafo introduzido por "sem ufanismo" venha destacar a participação do cantor brasileiro em contraste com o que o Locutor chame de "baladas monocórdias", "escravas de suas letras" e que são o "mal frequente desses chamados cantautores" que são os argentinos Charly García e Fito Paez ou o uruguaio Jorge Drexler do parágrafo ligeiramente anterior.

No caso de "Coração vagabundo", faixa cantada por Caetano, o locutor que se propõe não ufanista, destaca se tratar de uma "velha pérola" que "Juntos [Mercedes e Caetano] saboreiam os desenhos melódicos". O Locutor falha, portanto, porque ao 
mesmo tempo em que busca escrever "sem ufanismo" dá uma ênfase bastante específica ao trabalho do cantor brasileiro no álbum, além de um comentário que merece parágrafo à parte para a canção em dueto com Daniela Mercury. Se considerarmos que são dezenove duetos, além dos destaques das três baladas que considera ruins e dos dois cantores brasileiros, apenas menciona outro caso que "funciona” (o dueto com René Pérez) e outra canção que é "sonolenta” (gravada com Joaquín Sabina).

\section{Considerações finais}

o sentido não está localizado no enunciado, não é uma relação pura e simples do enunciado com o que está fora, mas é uma relação histórica com o que está fora" [...] e note-se que quando se está fazendo isso, não se está analisando o que o texto diz. Não se está interpretando texto. Está-se dizendo como o sentido está sendo construído (GUIMARÃES, 2013, p. 32 ).

A proposta do artigo foi estudar a produção de sentidos do texto "Sai DVD do último trabalho de Mercedes Sosa”, tratando-o com as categorias teóricometodológicas da semântica enunciativa de E. Guimarães. O texto está disponível no jornal O Globo e foi publicado em 2009 dando notícia do lançamento do CD e DVD "Cantora”, de Mercedes Sosa. Nossa análise se pautou nos conceitos de acontecimento, agenciamento do sujeito, reescrituração e articulação.

Podemos apontar alguns encaminhamentos que a análise nos permite concluir e que se relacionam com a produção do sentido construída nesse texto:

- O nome da cantora é reescriturado por repetição no texto pelo título, pela legenda da fotografia e nos dois primeiros parágrafos. Do terceiro parágrafo em diante, é reescriturado apenas por condensação, substituição por sinonímia ou anáfora e por elipse. Essa análise permite afirmar que a proximidade entre as reescriturações por repetição do começo do texto, a imagem e a questão do memorável fazem com que no desenvolver do texto o Locutor deixe de usar - à medida que avançam os parágrafos - a reescrituração por repetição para reescriturar "Mercedes Sosa” por apenas "Mercedes”, ou “cantora”, “argentina”, “intérprete”, "voz", ou usar elipses e anáforas. Cada vez que é reescriturado o nome da 
cantora por quaisquer dos mecanismos enunciativos mencionados acima a repetição deve ser interpretada como diferente de si.

- No que se refere à articulação: a expressão "Seu canto de cisne" e "sua morte" ajudam-nos a desambiguizar por articulação o título que enuncia "Sai DVD do último trabalho de Mercedes Sosa”, posto que o uso do verbo "sai" sugere a presentificação tanto do trabalho da cantora quanto de seu lançamento, o que não é possível já que a notícia é póstuma assim como o lançamento do DVD de que trata. Assim, "último trabalho" do título não designa "atual trabalho", mas "trabalho final”.

- A questão levantada pela articulação de "sem ufanismo" que introduz um parágrafo elogioso do texto em relação ao cantor Caetano Veloso demonstra o agenciamento do sujeito que, no dizer de Guimarães (2009), "não escolhe o modo de dizer algo, mas é agenciado a dizer" (GUIMARÃES, 2009, p. 50). O Locutor que assina o texto diz como locutor x que ocupa o espaço de crítico musical, mas não à revelia, um crítico musical brasileiro que escreve para um jornal brasileiro. Em outras palavras, levando em conta o aspecto argumentativo, por mais que se apresente como imparcial, ao preferir "sem ufanismo", o texto orienta para "parcial”. É como dizer "sem ufanismo" dizendo “com ufanismo", de modo que se instaura uma contradição: por um lado afirma que fará uma análise "sem ufanismo", mas simultaneamente, Caetano Veloso é destaque na fotografia que vem logo abaixo do título, é reescriturado por repetição na legenda dessa foto e em um hiperlink que redireciona ao vídeo no YouTube com a mencionada canção. Não fosse suficiente, tratase desse cantor em um longo parágrafo elogioso que se contrapõe a outro bastante crítico a respeito de cantores de outras nacionalidades.

\section{Referências}

BENVENISTE, Émile. Os níveis de análise linguística. In. BENVENISTE, É. Problemas de linguística geral I. Campinas: Pontes Editores, 2005. 
GUIMARÃES, Eduardo. A enumeração: funcionamento enunciativo e sentido. In. Cad.Est.Ling., Campinas, 51(1): 49-68, Jan./Jun. 2009.

. Domínio semântico de enunciação. In. GUIMARÃES, E. A palavra. Forma e sentido. Campinas: Pontes, 2007.

. Semântica do acontecimento: um estudo enunciativo da designação. Campinas: Pontes, 2002.

Análise de textos: procedimentos, análises, ensino. Campinas: Editoras RG, 2011.

. Semântica da enunciação e textualidade. In. SCHREIBER DA SILVA, S. M.; MACHADO, C. P. Estudos dos sentidos na semântica e no discurso. São Carlos: Pedro \& João Editores, 2013.

SCHREIBER DA SILVA, S. M.; MACHADO, C. P. Semântica do acontecimento: princípios teóricos, metodológicos e análises. In. BARONAS, R.L. Estudos discursivos à brasileira: uma introdução. Campinas: Pontes, 2016.

Anexo

Anexo 1: "Sai DVD do último trabalho de Mercedes Sosa".

\section{Sai DVD do último trabalho de Mercedes Sosa}

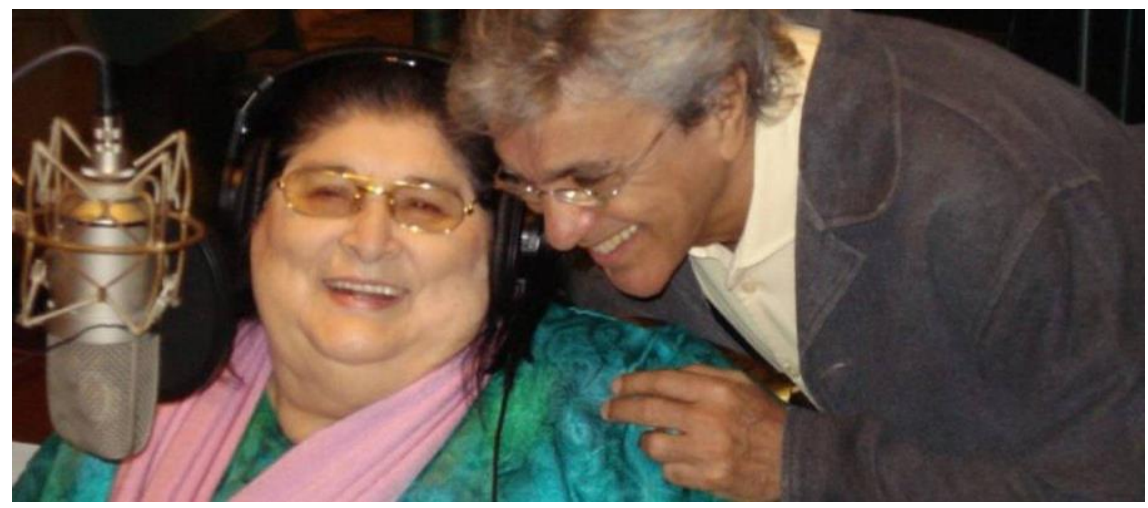

Mercedes Sosa com Caetano Veloso Divulgação

POR ANTÔNIO CARLOS MIGUEL

25/11/2009 0:00 / ATUALIZADO 10/11/2011 11:29

Num de seus depoimentos, no documentário em DVD que acompanha o disco "Cantora" (Sony Music), Mercedes Sosa diz que, se não fosse a ideologia, ela seria apenas mais uma cantora. Verdade confirmada por seu trajeto e sua postura política, mas que também permite uma observação contrária: não fosse uma grande intérprete, com seu belo timbre de 
contralto, e a sensibilidade na escolha de repertório e acompanhantes, ela não passaria de mais uma artista engajada.

Assista a Mercedes Sosa cantando "Coração vagabundo" com Caetano Veloso

Seu canto de cisne, reunindo 19 duetos com artistas hispano-americanos de diferentes gerações e estilos, "Cantora" foi produzido no ano passado, num estúdio de Buenos Aires - com eventuais gravações nos países de alguns de seus convidados -, e, mesmo que tenha conteúdo irregular, serve como um belo testamento dessa voz que tantas fronteiras derrubou.

A voz estava fragilizada, sem atingir algumas notas, mas Mercedes, então com 73 anos e muitos quilos a mais, sempre sentada - seja nas entrevistas ou gravando -, tinha experiência e talento para driblar as dificuldades físicas. O DVD, dirigido por Rodrigo H. Vila, documenta passo a passo a gravação deste que acabou sendo o último disco em vida da cantora - e que, no início de novembro, um mês após a sua morte, ganhou o troféu de Âlbum Folclórico na décima edição do Grammy Latino.

É um conceito bem elástico de "folclórico" - mesmo que esse viesse sendo o campo habitual da intérprete, nascida em 9 de julho de 1935, em Tucumán, e que lançou seu primeiro LP em 1962, "La voz de lazafra" -, já que há em "Cantora" a presença de muitos representantes da música pop hispano-americana contemporânea. E as baladas de gente como os argentinos Charly Garcia ("Desarma y sangra") e Fito Paez ("Zamba delcielo") e o uruguaio Jorge Drexler ("Sea") soam monocórdias, com melodias por demais escravas de suas letras, um mal frequente na produção desses chamados cantautores.

Sem ufanismo, um dos destaques é o encontro com Caetano Veloso em "Coração vagabundo", faixa gravada no Rio, aproveitando a passagem da argentina pelo Brasil em outubro de 2008, quando recebeu a insígnia da Ordem do Mérito Cultural, em cerimônia realizada no Teatro Municipal. Juntos no estúdio, eles saboreiam os desenhos melódicos da velha pérola de Caetano, que Mercedes canta num português com leve sotaque.

O encontro, virtual, com Daniela Mercury - que gravou a sua parte sozinha, em Salvador - é outro bom momento, graças à força perene de "O que será", em versão, com arranjo do guitarrista Jorge Giuliano, que reforça o sotaque caribenho presente na composição de Chico Buarque.

Há também a tentativa, bem-sucedida, por sinal, de aproximar Mercedes do rap, em "Canción para unniñoenlacalle" - ela cuida da melodia enquanto René Pérez, da dupla portoriquenha Calle 13, da parte falada, com a habitual temática sociopolítica que caracteriza o estilo. Funciona. Bem melhor do que o encontro com o espanhol Joaquín Sabina em "Violetas para Violeta", balada sonolenta, com letra baseada em canção da chilena Violeta Parra, mas que patina nas boas intenções. Não basta ser engajado.

Disponível em: $<$ https://oglobo.globo.com/cultura/sai-dvd-do-ultimo-trabalho-de-mercedessosa-3143132\#ixzz5IYXLZuo3>. Acesso 16 de jun. de 2018.

\footnotetext{
* Doutorando em Linguística pela Universidade Federal de São Carlos UFSCar
} 